\title{
Aloe sterol supplementation improves skin elasticity in Japanese men with sunlight-exposed skin: a I2-week double-blind, randomized controlled trial
}

This article was published in the following Dove Press journal:

Clinical, Cosmetic and Investigational Dermatology

10 November 2016

Number of times this article has been viewed

Miyuki Tanaka'

Yuki Yamamoto

Eriko Misawa'

Kazumi Nabeshima'

Marie Saito'

Koji Yamauchi'

Fumiaki Abe'

Fukumi Furukawa ${ }^{2}$

'Functional Food Ingredients Department, Food Ingredients \& Technology Institute, Morinaga Milk Industry Co., Ltd., Zama, Kanagawa, 2Department of Dermatology, Wakayama Medical University, Kimiidera, Wakayama, Japan
Correspondence: Miyuki Tanaka Functional Food Ingredients Department, Food Ingredients \& Technology Institute, Morinaga Milk Industry Co., Ltd., I-83, Higashihara 5-chome, Zama, Kanagawa 252-8583, Japan

Tel +8 I 462523070

Fax +8I 462523049

Email m_tanaka@morinagamilk.co.jp
Background/objective: Recently, it was confirmed that the daily oral intake of plant sterols of Aloe vera gel (Aloe sterol) significantly increases the skin barrier function, moisture, and elasticity in photoprotected skin. This study aimed to investigate whether Aloe sterol intake affected skin conditions following sunlight exposure in Japanese men.

Methods: We performed a 12-week, randomized, double-blind, placebo-controlled study to evaluate the effects of oral Aloe sterol supplementation on skin conditions in 48 apparently healthy men (age range: $30-59$ years; average: 45 years). The subjects were instructed to expose the measurement position of the arms to the sunlight outdoors every day for 12 weeks. The skin parameters were measured at 0 (baseline), 4, 8, and 12 weeks.

Results: Depending on the time for the revelation of the sunlight, the $b^{*}$ value and melanin index increased and the skin moisture decreased. After taking an Aloe sterol tablet daily for 12 weeks, the skin elasticity index (R2, R5, and R7) levels were significantly higher than the baseline value. There were no differences between the groups in these skin elasticity values. In the subgroup analysis of subjects aged $<46$ years, the change in the R5 and R7 was significantly higher in the Aloe group than in the placebo group at 8 weeks $(P=0.0412$ and $P=0.0410$, respectively). There was a difference in the quantity of sun exposure between each subject, and an additional clinical study that standardizes the amount of ultraviolet rays is warranted. No Aloe sterol intake-dependent harmful phenomenon was observed during the intake period. Conclusion: Aloe sterol ingestion increased skin elasticity in the photodamaged skin of men aged $<46$ years.

Keywords: Aloe vera, Aloe sterol, skin elasticity, photodamage, Japanese men

\section{Introduction}

Skin aging is caused by the following two main progressive processes: 1) intrinsic and 2) extrinsic processes. ${ }^{1}$ The extrinsic process is caused by environmental aggressors, also known as "photoaging". Intrinsic and extrinsic aging (photoaging) of the skin are likely driven by similar biological and molecular mechanisms. ${ }^{2}$ The formation of reactive oxygen species (ROS) and induction of matrix metalloproteinases (MMPs) are the common factors of both types of skin aging. ${ }^{3}$ Skin photoaging is the result of preventable chronic exposure to ultraviolet (UV) radiation combined with intrinsic aging. ${ }^{4}$ Major changes in skin photoaging occur within the dermis.

The age-related loss of cutaneous elasticity is associated with the reconstruction of the dermis extracellular matrix and an increased incidence of both skin tears and 
pressure ulcers. ${ }^{5,6}$ Varani et $\mathrm{al}^{7}$ reported that reduced collagen synthesis in chronologically aged skin reflects at least two different underlying mechanisms: 1) aging of cellular fibroblasts and 2) reduced mechanical stimulation. Moreover, collagen fibers are fragmented by exposure to UV light and/or aging. ${ }^{8}$

Aloe vera (Aloe barbadensis Miller) gel is obtained from the mesophyll of the plant. Aloe vera gel contains polysaccharides, amino acids, lipids, plant sterols, tannins, and enzymes that have been routinely used as herbal medicines. ${ }^{9,10}$ Moreover, Aloe sterol is present in the Aloe vera gel and possesses a unique efficacy. ${ }^{11}$ Structurally, Aloe sterol falls into two groups of compounds: 1) lophenol (lophenol, 24-methyl-lophenol, and 24-ethyl-lophenol) and 2) cycloartane (cycloartenol and 24-methylene-cycloartanol). Aloe sterol can activate the peroxisome proliferator-activated receptor (PPAR) ligands. ${ }^{12}$ Barlaka et $\mathrm{al}^{13}$ reported that the novel connection between PPAR signaling and MMP downregulation in cardiac myocytes might be involved in the management of oxidative stress-induced cardiac dysfunction. Furthermore, our recent study demonstrated that Aloe sterol significantly prevented an increase in the total protein expression of MMP-2 (active and pro) and MMP-9 (active and pro) in UVB-irradiated mice. ${ }^{14}$

Our previous study revealed that the levels of skin moisture, skin elasticity, and collagen scores in the Aloe sterol group were higher than those of the placebo groups. ${ }^{15}$ Furthermore, ultrasound echogenicity revealed that Aloe sterol intake increased the amount of collagen in the dermis.

In the present study, we examined the influence of Aloe sterol intake on sunlight-exposed skin conditions of men who did not use sunscreen during the summer season in Japan.

\section{Methods}

\section{Trial registration}

UMIN Clinical Trial Registry: UMIN000018384. Registered on July 7, 2015.

\section{Test samples}

Table 1 presents the composition of Aloe sterol and the control tablets. The amount of Aloe sterols per daily dose (five tablets) was $40 \mu \mathrm{g}$. The Aloe vera gel powder was prepared by drying the mesophyll of Aloe vera plants. In the placebo tablets, the Aloe vera gel powder was replaced with dextrin.

\section{Study design}

This study was conducted as a monocentric, double-blinded, randomized, placebo-controlled supplementation study on the effects of Aloe sterol on skin elasticity and hydration after
Table I Ingredient composition of the tablets in this study

\begin{tabular}{lll}
\hline & $\begin{array}{l}\text { Placebo } \\
\text { (mg/5 tablets) }\end{array}$ & $\begin{array}{l}\text { Aloe sterol } \\
\text { (mg/5 tablets) }\end{array}$ \\
\hline AVGP* & 0 & 500 \\
Dextrin & 500 & 0 \\
Citric acid & 100 & 100 \\
Maltose & 1417.5 & 1417.5 \\
Sour milk & 25 & 25 \\
Cellulose & 250 & 250 \\
Calcium phosphate & 12.5 & 12.5 \\
Flavor & 87.5 & 87.5 \\
Glycerin fatty acid & 50 & 50 \\
Sugar ester & 50 & 50 \\
Food color & 5 & 5 \\
\hline
\end{tabular}

Note: *AVGP $(500 \mathrm{mg})$ contains $40 \mu \mathrm{g}$ of Aloe sterol. Abbreviation: AVGP, Aloe vera gel powder.

12 weeks of daily Aloe sterol intake. The study protocol was examined and approved by the institutional review board of the Medical Corporation Bokushinkai CLINTEXE Clinic (Tokyo, Japan) and was conducted according to the guidelines of the Declaration of Helsinki 2013. Before beginning the study, written informed consent was obtained from all the participants, and they were free to withdraw from the study at any time without obligation. This study was carried out from July 2015 to October 2015, during summer to autumn in Japan.

\section{Subjects}

A total of 48 apparently healthy adult Japanese men (age: 30-59 years) who were outdoors during the daytime for $2-5$ hours were randomly assigned to the placebo $(\mathrm{n}=24)$ or Aloe sterol $(\mathrm{n}=24)$ groups. Each participant was identified by a code that was randomly selected using a computer-generated permutation procedure. The codes were sequentially allocated to the participants in the order in which they were enrolled. After all the measurements had been completed, the randomization codes were disclosed to the investigators. The study participants, investigators, staff members, and laboratory technicians were all blinded to the group assignment.

\section{Inclusion criteria}

The inclusion criteria were as follows: healthy men of age $30-59$ years and individuals who were outdoors during the daytime for $2-5$ hours.

\section{Exclusion criteria}

The exclusion criteria were as follows: individuals who regularly used cosmetics or consumed food that adversely affected skin conditions (e.g., hyaluronic acid, ceramide, and collagen peptide); those who used cosmetics and creams, except sunscreen on the arms; those whose arms had a skin 
abnormality that required treatment; those with allergic diseases with sleep deprivation or a sleep disorder; those with skin diseases; those who excessively ingest alcohol and are current smokers (smoking $>20$ cigarettes per day); those with a history of serious skin, liver, kidney damage, heart, lungs, endocrine, and metabolic diseases; those with a history of drug or serious food allergy; those with simultaneous participation in other clinical studies; and those judged inappropriate for the study based on subject background, physical findings, or medical examination.

\section{Measurement of skin parameters}

The test areas were designated as the inner side of one forearm. The skin parameters were examined at weeks 0,4 , 8 , and 12 of the treatment period. Measurements were performed under the standard conditions of room temperature $\left(20^{\circ} \mathrm{C}-22^{\circ} \mathrm{C}\right)$ and humidity $(45 \%-55 \%)$. The participants were allowed to adapt to the room conditions for at least 20 minutes before the examination. Each skin color index was determined using a spectrophotometer CM-2600d (Konica Minolta, Tokyo, Japan). CM-2600d was used for skin color measurement after the calibration using a certificated white plate. The $L^{*}$ value provides the relative lightness ranging from total black $\left(L^{*}=0\right)$ to total white $\left(L^{*}=100\right)$; the $a^{*}$ value represents the balance between red (positive value) and green (negative value); and the $b^{*}$ value represents the balance between yellow (positive value) and blue (negative value). ${ }^{16}$ A Corneometer CM 825 (Courage and Khazaka Electronic $\mathrm{GmbH}$, Cologne, Germany) was used to determine the skin hydration level. Skin elasticity was determined using a Cutometer MPA 580 (Courage and Khazaka Electronic $\mathrm{GmbH}$ ). The elastic measurement was evaluated according to the following parameters: R2 (gross elasticity), R5 (net elasticity), and R7 (biological elasticity). The values of skin elasticity are known to decrease with aging. We performed a stratified analysis of skin elasticity in subjects aged $<46$ years (median age).

\section{Statistical analysis}

The skin parameters were analyzed using the analysis of covariance with the treatment effect and baseline skin parameters as covariates. The differences with a $P<0.05$ in a two-tailed $t$-test were considered to be significant.

\section{Results \\ Subject demographics}

A total of 48 apparently healthy men were initially enrolled into the study, none of whom met the exclusion criteria.
Therefore, all 48 men were randomly assigned to the placebo $(n=24)$ or the Aloe sterol $(n=24)$ group in a double-blind manner. One participant in the Aloe sterol group violated compliance ( $20 \%$ of intake rate during 0-4 weeks) after the baseline tests. Therefore, we analyzed the data from 47 subjects. The number of subjects of the age groups 30-39, 40-49, and 50-59 years were nine, six, and nine, respectively, in the placebo group and seven, seven, and nine, respectively, in the Aloe sterol group. The two groups presented with comparable baseline characteristics (Table 2). There were no significant differences between the two groups. No significant treatment-related adverse events were reported with respect to blood lipid or biochemical parameters during the 12-week study period (data not shown).

\section{Skin color value}

The subjects included healthy adult men with the habit of being active outdoors for 2-5 hours per day in their daily life. They were instructed to discontinue the use of cosmetics, including sunscreen, at the measurement site (forearm) during the test period. We observed an increase in the melanin index values at 4,8 , and 12 weeks in the placebo group and at 4 and 12 weeks of the Aloe sterol group compared with that at baseline (Table 3 ). Similar to the observed changes in the melanin index values, the $b^{*}$ values increased at 4,8 , and 12 weeks in both the placebo and Aloe sterol groups. In contrast, a decrease in the $L^{*}$ values (brightness) was observed in both the placebo and Aloe sterol groups during the test period. There were no differences between both groups for the values of $L^{*}, a^{*}, b^{*}$, and the melanin index at the site used for the skin measurements. Contrary to the increase in the melanin index and $b^{*}$ values, we observed a decrease in the skin hydration of the forearm that was exposed to sunlight at 8 and 12 weeks in both groups (data not shown).

Table 2 Demographic and baseline characteristics

\begin{tabular}{lll}
\hline Characteristic & $\begin{array}{l}\text { Placebo } \\
(\mathbf{n = 2 4})\end{array}$ & $\begin{array}{l}\text { Aloe sterol } \\
(\mathbf{n}=23)\end{array}$ \\
\hline Age (years) & $44.6 \pm 8.7$ & $45.4 \pm 8.5$ \\
Height $(\mathrm{cm})$ & $170.07 \pm 4.03$ & $170.76 \pm 5.54$ \\
Body weight $(\mathrm{kg})$ & $64.65 \pm 6.61$ & $65.07 \pm 9.02$ \\
BMI & $22.33 \pm 1.97$ & $22.31 \pm 2.80$ \\
Systolic blood pressure $(\mathrm{mmHg})$ & $119.1 \pm 12.3$ & $123.0 \pm 12.7$ \\
Diastolic blood pressure $(\mathrm{mmHg})$ & $75.9 \pm 8.2$ & $75.7 \pm 9.5$ \\
Pulse rate (bpm) & $63.8 \pm 11.3$ & $61.7 \pm 8.8$ \\
\hline
\end{tabular}

Notes: Data are expressed as mean \pm SD. There were no significant differences in the skin parameters between the two groups.

Abbreviations: BMI, body mass index; SD, standard deviation. 
Table 3 Skin color values

\begin{tabular}{|c|c|c|c|c|c|c|}
\hline Item & Group & $\mathbf{n}$ & 0 week & 4 weeks & 8 weeks & 12 weeks \\
\hline \multirow[t]{2}{*}{$L^{*}$ value } & Aloe sterol & 23 & $62.56 \pm 4.87$ & $61.69 \pm 4.7 I^{* *}$ & $61.95 \pm 4.13$ & $61.93 \pm 3.82$ \\
\hline & Placebo & 24 & $61.88 \pm 2.94$ & $60.43 \pm 3.14^{* *}$ & $60.68 \pm 2.52^{* *}$ & $60.93 \pm 2.24 *$ \\
\hline \multirow[t]{2}{*}{$a^{*}$ value } & Aloe sterol & 23 & $6.21 \pm 2.28$ & $6.48 \pm 2.00$ & $6.20 \pm 1.99$ & $6.80 \pm 1.93$ \\
\hline & Placebo & 24 & $6.43 \pm 1.48$ & $7.19 \pm 1.61 * *$ & $6.80 \pm 1.38$ & $7.26 \pm 1.38 * *$ \\
\hline \multirow[t]{2}{*}{$b^{*}$ value } & Aloe sterol & 23 & $16.59 \pm 2.30$ & $17.02 \pm 2.39 *$ & $17.22 \pm 2.26 * *$ & $17.80 \pm 2.04 * *$ \\
\hline & Placebo & 24 & $17.02 \pm 1.77$ & $|7.8| \pm 1.64^{* *}$ & $17.75 \pm 1.42 *$ & $18.22 \pm 1.34 * *$ \\
\hline \multirow[t]{2}{*}{ Melanin index } & Aloe sterol & 23 & $0.9239 \pm 0.3105$ & $0.9807 \pm 0.3162 * *$ & $0.9645 \pm 0.2936$ & $1.0080 \pm 0.2624^{* *}$ \\
\hline & Placebo & 24 & $0.9557 \pm 0.2028$ & $1.0677 \pm 0.2142 * *$ & $|.037| \pm 0.169 \mid * *$ & $1.0628 \pm 0.1466 * *$ \\
\hline
\end{tabular}

Notes: The skin color index was determined using a spectrophotometer at the forearm. Data are expressed as mean $\pm S D$. $* P<0.05$, $* * P<0.005$ different from week 0 .

Abbreviation: SD, standard deviation.

Table 4 Analysis results of the skin elasticity parameters (R2, R5, and R7) on the forearm

\begin{tabular}{lllllll}
\hline Item & Group & $\mathbf{n}$ & 0 week & 4 weeks & 8 weeks & I2 weeks \\
\hline R2 (\%, gross elasticity) & Aloe sterol & 23 & $0.823 \pm 0.029$ & $0.835 \pm 0.037$ & $0.837 \pm 0.035^{*}$ & $0.843 \pm 0.043^{*}$ \\
& Placebo & 24 & $0.822 \pm 0.054$ & $0.827 \pm 0.039$ & $0.826 \pm 0.042$ & $0.837 \pm 0.044^{*}$ \\
R5 (\%, net elasticity) & Aloe sterol & 23 & $0.760 \pm 0.053$ & $0.819 \pm 0.090^{* *}$ & $0.808 \pm 0.058^{* *}$ & $0.826 \pm 0.076^{* *}$ \\
& Placebo & 24 & $0.748 \pm 0.09$ I & $0.784 \pm 0.098^{*}$ & $0.772 \pm 0.100$ & $0.815 \pm 0.11 I^{*}$ \\
R7 (\%, biological elasticity) & Aloe sterol & 23 & $0.553 \pm 0.038$ & $0.569 \pm 0.05 I^{*}$ & $0.568 \pm 0.046$ & $0.575 \pm 0.060^{*}$ \\
& Placebo & 24 & $0.546 \pm 0.067$ & $0.555 \pm 0.066$ & $0.546 \pm 0.066$ & $0.570 \pm 0.068^{*}$ \\
\hline
\end{tabular}

Notes: R2, R5, and R7 values were determined using a Cutometer on the forearm. Data are expressed as mean $\pm S E$. $* P<0.05$, $* * P<0.005$, different from week 0 . Abbreviation: SE, standard error.

\section{Skin elasticity}

Table 4 shows the results of the skin elasticity parameters ( $R 2$, $\mathrm{R} 5$, and R7) on the forearm. The R2 parameters of the Aloe sterol group were higher at 8 and 12 weeks compared with the baseline values. The placebo group was higher at 12 weeks compared with the baseline values. After having taken Aloe sterol tablets daily for 4 weeks, the R5 level was significantly higher than the baseline value until 12 weeks. The R5 of the placebo group was also higher at 4 and 12 weeks compared with the baseline value. The R7 of the Aloe sterol group was higher at 4 and 12 weeks compared with the baseline value. The R7 of the placebo group was higher at 12 weeks compared with the baseline value. There was no difference between both groups in the R2, R5, and R7 values.

The values of R2, R5, and R7 are known to decrease with aging. ${ }^{17}$ Therefore, we divided each group into two groups, with one including subjects $<$ median age (46 years) and another including subjects $>$ median age. We then performed a stratified analysis of subjects aged $<46$ years (young placebo group: $\mathrm{n}=11$ and young Aloe sterol group: $\mathrm{n}=12)$. The change in the $\mathrm{R} 2$ at 12 weeks $(0.024 \% \pm 0.009 \%)$ was significantly higher in the young Aloe sterol group than that of the baseline value (Figure 1). In contrast, the placebo tablets did not significantly affect the change in the $\mathrm{R} 2$ value at 12 weeks $(0.009 \% \pm 0.008 \%)$. The change in the R5 of the young Aloe sterol group was significantly greater at 4,8 , and 12 weeks $(0.075 \% \pm 0.015 \%, 0.057 \% \pm 0.016 \%$, and $0.065 \% \pm 0.022 \%$,

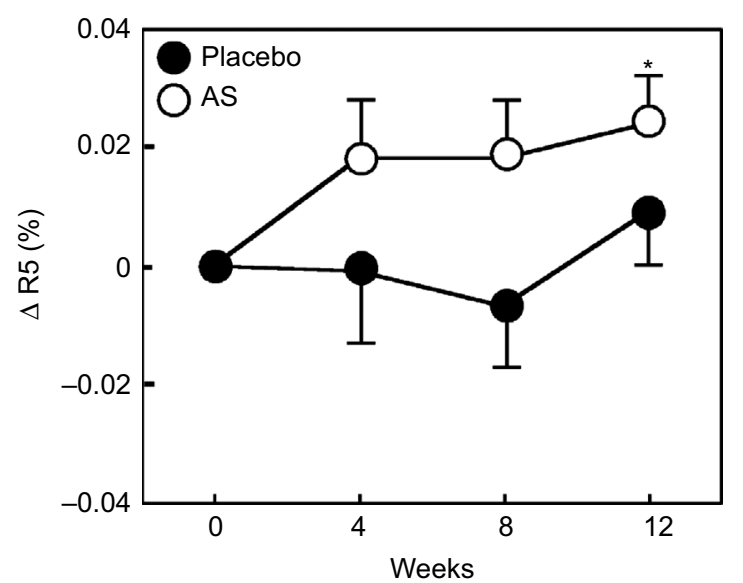

Figure I The change in the R2 (gross elasticity) of participants aged $<46$ years during the treatment period.

Notes: The data are expressed as mean \pm SE (placebo $n=12$ and Aloe sterol $n=11$ ). $* P<0.05$ vs baseline values.

Abbreviations: AS, Aloe sterol; SE, standard error.

respectively) than the baseline value (Figure 2). In contrast, the change in the R5 at 4,8 , and 12 weeks $(0.033 \% \pm 0.021 \%$, $0.005 \% \pm 0.017 \%$, and $0.045 \% \pm 0.021 \%$, respectively) was not significantly affected by the placebo tablets. Furthermore, the change in the R5 was significantly higher in the Aloe group than in the placebo group at 8 weeks for this age group ( $P=0.0412$; Figure 2$)$. The change in the $\mathrm{R} 7$ of the young Aloe sterol group was significantly greater at 4 , 8 , and 12 weeks $(0.024 \% \pm 0.005 \%, 0.023 \% \pm 0.010 \%$, and $0.027 \% \pm 0.013 \%$, respectively) than the baseline value. 


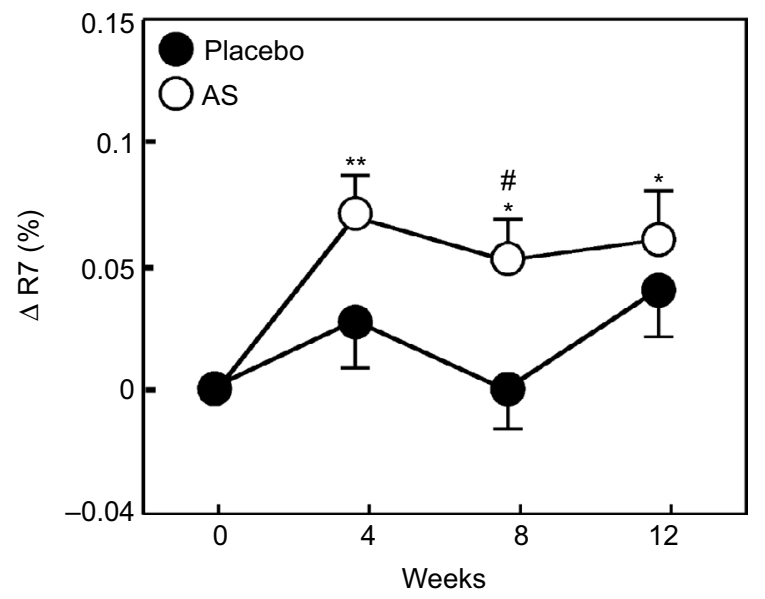

Figure 2 The change in the R5 (skin net elasticity) of participants aged < 46 years during the treatment period.

Notes: The data are expressed as mean \pm SE (placebo $n=12$ and Aloe sterol $n=11$ ). $* P<0.05,{ }^{* *} P<0.005$ vs baseline values. ${ }^{*} P<0.05$ vs placebo group values.

Abbreviations: AS, Aloe sterol; SE, standard error.

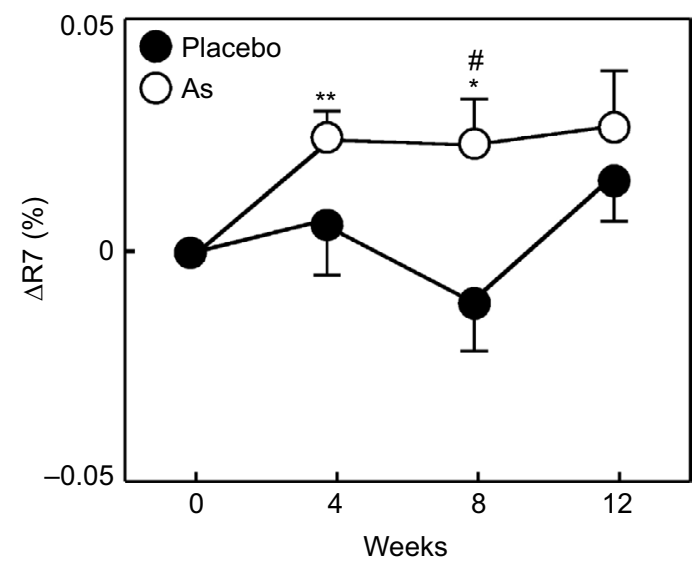

Figure 3 The change in the R7 (skin biological elasticity) of participants aged $<46$ years during the treatment period.

Notes: The data are expressed as mean \pm SE (placebo $n=12$ and Aloe sterol $n=11$ ). ${ }^{*} P<0.05,{ }^{* *} P<0.005$ vs baseline values. ${ }^{*} P<0.05$ vs placebo group values.

Abbreviations: AS, Aloe sterol; SE, standard error.

In contrast, the change in the $\mathrm{R} 7$ at 4,8 , and 12 weeks $(0.007 \% \pm 0.013 \%,-0.011 \% \pm 0.012 \%$, and $0.016 \% \pm 0.010 \%$, respectively) was not significantly affected by the placebo tablets. Furthermore, the change in the R7 was significantly higher in the Aloe sterol group than in the placebo group at 8 weeks in this age group $(P=0.0410$; Figure 3$)$.

\section{Discussion}

In general, the $b^{*}$ and $L^{*}$ values show a significant correlation with the perception of tanning. ${ }^{18,19}$ During this study period, the subject was instructed that the measurement position (forearm) should be exposed to sunlight for 2-5 hours per day. Therefore, we also observed a decrease in the $L^{*}$ value and an increase in the $b^{*}$ value depending on the increase in the melanin index value. The midsummer months (June and August) in 2015 in Japan were $\sim 8$ weeks after the study com- menced, and the UV index score was $\sim 9$ (strong) to 10 (very strong; data from the homepage of the Japan Meteorological Agency $^{20}$ ).

Our recent clinical study suggested that the Aloe sterol intake induced a significant increase in the skin hydration of Japanese women's skin that was protected from sunlight by clothing. ${ }^{15}$ In a basic research report, we suggested that the Aloe sterols prevented significant UVB irradiation-induced decreases in skin hydration, elasticity, and hyaluronic acid synthase 2 (Has2) in hairless mice. ${ }^{14}$ In this study, we did not observe the preventive efficacy of Aloe sterol ingestion on a decrease in skin moisture by exposure to sunlight. Since the study involved the natural exposure of sunlight in accordance with the lifestyle of each subject, we were not able to ensure that each subject received the same amount of sunlight. Table S1 presents the difference in the quantity of sun exposure between each subject. Thus, to examine the efficacy of the ingestion of Aloe sterol on skin photodamage, additional clinical studies that standardize the amount of UV rays for each subject is required.

Koyano et $\mathrm{al}^{21}$ indicated that an abundance of type 4 collagen in the dermis was statistically lower in patients with skin tears than in those without skin tears. Therefore, a reduction in the dermis collagen density is associated with skin elasticity and fragility. Therefore, skin elasticity is one of the indexes of the healthy dermis structure.

Cho et $\mathrm{al}^{22}$ examined the immunostaining and RT-PCR of the buttock skin of Korean women, before and after Aloe vera gel powder intake. The authors suggested that the ingestion of Aloe vera gel powder increases type 1 procollagen in human skin tissue. Moreover, Aloe sterol promotes collagen production and increases the synthesis of type I and type III collagen in human dermal fibroblasts. ${ }^{23}$ Furthermore, our recent clinical trial demonstrated that the results of an ultrasonography evaluation suggest that the intake of $40 \mu \mathrm{g}$ of Aloe sterol increased collagen score within the dermis. ${ }^{15}$

The previous study reported significant increases in the skin elasticity R2 and R7 parameters after 90 days of Aloe vera gel powder intake. ${ }^{22}$ Similarly, the results of our recent study revealed that the dietary supplementation of $40 \mu \mathrm{g}$ of Aloe sterol increased the skin parameters of R2, R5, and R7 in women. ${ }^{16}$ In this study, we demonstrate that a daily oral dose of $40 \mu \mathrm{g}$ of Aloe sterols significantly increased skin elasticity (R5 and R7) in men aged $<46$ years compared with the placebo group.

Gerhardt et $\mathrm{al}^{17}$ reported that the skin elasticity (R2, R5, and R7) of young men (age range: $17-46$ years) is higher than that of older men (age range: 66-95 years). They discussed 
that the disintegration could explain the decrease in the biological elasticity of R7 in the elderly, the increased porosity of the elastic fibers, ${ }^{24,25}$ and a decrease in R5 demonstrates an impaired ability of aged skin to return to its initial state after vacuum. ${ }^{26}$ The sun-protected dermis of men is much thicker than that of women (1.8-fold). In contrast, epidermal and subcutaneous tissues are thicker in women (3.5- and 10-fold, respectively). ${ }^{27}$ In previous studies, the analysis of sun-protected skin obtained from young and elderly Caucasian donors revealed biomarkers of endogenous human skin aging in both genders and indicated that the process of aging in men may significantly differ from that in women. ${ }^{28}$ In these subjects, a change in the skin conditions was independently affected by intrinsic and extrinsic (i.e., photoaging) processes. Therefore, additional studies are required to examine the efficacy of Aloe sterol in older men.

Since the skin was exposed to UV light according to the activities of everyday life for each of the subjects, this study has some limitations. There was a broad range in the amount of UV exposure for each subject. Furthermore, the ratio of subjects exposed to sunlight gradually decreased after the fourth week from the start of the study. After 8-12 weeks, the ratio that protected the prescribed time was $30 \%$ in the placebo group and 50\% in the Aloe sterol group (Table S1). We considered that the additional examination that considered various conditions is necessary to investigate the ability to affect skin condition by intake of Aloe sterol in the subjects who are exposed to the same amount of UV rays.

Minimal erythema dose (MED) is the amount of UV radiation that will produce minimal erythema (sunburn or redness caused by engorgement of capillaries) of an individual's skin within a few hours following UV exposure. Sun protection factor (SPF) is the ratio of MED after sunscreen application and baseline (untreated) MED, whereas SPF values generally denote the efficiency of a sunscreen to protect the skin from UV radiation. ${ }^{29}$ To investigate the ability of the intake of Aloe sterol to prevent damages to the skin caused by UV irradiation, it was considered necessary to perform MED and/or SPF tests.

UV irradiation of human skin induces ROS, leading to the activation of ROS-sensitive signaling kinases in keratinocytes and fibroblasts. ${ }^{30-32}$ Previous studies suggested that Aloe vera has anti-inflammatory and antioxidant effects. ${ }^{33,34}$ Aloe sterol derived from Aloe vera may also have such anti-inflammatory and antioxidant effects, and further investigation is warranted.

The results of this double-blind clinical trial demonstrated that the daily oral intake of $40 \mu \mathrm{g}$ Aloe sterol significantly increased the skin elasticity of UV-exposed men aged $<46$ years.

\section{Disclosure}

The authors report no conflicts of interest in this work.

\section{References}

1. El-Domyati M, Attia S, Saleh F, et al. Intrinsic aging vs. photoaging: a comparative histopathological, immunohistochemical, and ultrastructural study of skin. Ageing Res Rev. 2002;1(4):705-720.

2. Rittié L, Fisher GJ. UV-light-induced signal cascades and skin aging. J Eur Acad Dermatol Venereol. 2011;25(8):873-884.

3. Kohl E, Steinbauer J, Landthaler M, Szeimies RM. Skin ageing. J Eur Acad Dermatol Venereol. 2011;25(8):873-884.

4. Trautinger F. Mechanisms of photodamage of the skin and its functional consequences for skin aging. Clin Exp Dermatol. 2001;26(7):573-577.

5. Baranoski S. Skin tears: the enemy of frail skin. Adv Skin Wound Care. 2000;13(3Pt1):123-126.

6. Farage MA, Miller KW, Berardesca E, Maibach HI. Clinical implications of aging skin: cutaneous disorders in the elderly. Am J Clin Dermatol. 2009;10(2):73.

7. Varani J, Dame MK, Rittie L, et al. Decreased collagen production in chronologically aged skin: roles of age-dependent alteration in fibroblast function and defective mechanical stimulation. Am J Pathol. 2006;168(6):1861-1868.

8. Tzellos TG, Klagas I, Vahtsevanos K, et al. Extrinsic ageing in the human skin is associated with alterations in the expression of hyaluronic acid and its metabolizing enzymes. Exp Dermatol. 2009;18(12): 1028-1035.

9. Shelton RM. Aloe vera. Its chemical and therapeutic properties. Int $J$ Dermatol. 1991;30(10):679-683.

10. Vogler BK, Ernst E. Aloe vera: a systematic review of its clinical effectiveness. Br J Gen Pract. 1999;49(447):823-828.

11. Tanaka M, Misawa E, Ito Y, et al. Identification of five phytosterols from Aloe vera gel as anti-diabetic compounds. Biol Pharm Bull. 2006;29(7):1418-1422.

12. Nomaguchi K, Tanaka M, Misawa E, et al. Aloe vera phytosterols act as ligands for PPAR and improve the expression levels of PPAR target genes in the livers of mice with diet-induced obesity. Obes Res Clin Pract. 2011;5(3):190-201.

13. Barlaka E, Görbe A, Gáspár R, Pálóczi J, Ferdinandy P, Lazou A. Activation of PPAR $\beta / \delta$ protects cardiac myocytes from oxidative stressinduced apoptosis by suppressing generation of reactive oxygen/nitrogen species and expression of matrix metalloproteinases. Pharmacol Res. 2015;95-96:102-110.

14. Saito M, Tanaka M, Misawa E, et al. Oral administration of Aloe vera gel powder prevents UVB-induced decrease in skin elasticity via suppression of overexpression of MMPs in hairless mice. Biosci Biotechnol Biochem. 2016;80(7):1416-1424.

15. Tanaka M, Yamamoto Y, Misawa E, et al. Effects of Aloe sterol supplementation on skin elasticity, hydration, and collagen score: a 12-week double-blind, randomized, controlled trial. Skin Pharmacol Physiol. In press.

16. Rosbertson AR. The CIE 1976 color-difference formulae. Color Res Appl. 1977;2(1):7-11.

17. Gerhardt L-C, Lenz A, Spencer ND, Münzer T, Derler S. Skin-textile friction and skin elasticity in young and aged persons. Skin Res Technol. 2009;15(3):288-298.

18. Seitz JC, Whitmore CG. Measurement of erythema and tanning responses in human skin using a tri-stimulus colorimeter. Dermatologica. 1988;177(2):70-75.

19. Clarys P, Alewaeters K, Lambrecht R, Barel AO. Skin color measurements: comparison between three instruments: the chromameter $(\mathrm{R})$, the dermaspectrometer (R) and the mexameter (R). Skin Res Technol. 2000;6(4):230-238.

20. Japanese Meteorological Agency [homepage on the Internet]: Monthly change graph of the UV index (observation level) maximum on the day of the Tsukuba spot of July, 2015 (pull-down choice). Available from: http://www.data.jma.go.jp/gmd/env/uvhp/link_daily_uvindex_monthly_obs.html. Accessed May 3, 2016. 
21. Koyano Y, Nakagami G, Iizaka S, et al. Exploring the prevalence of skin tears and skin properties related to skin tears in elderly patients at a long-term medical facility in Japan. Int Wound J. 2016;13(2): 189-197.

22. Cho S, Lee S, Lee M-J, et al. Dietary Aloe vera supplementation improves facial wrinkles and elasticity and it increases the type 1 procollagen gene expression in human skin in vivo. Ann Dermatol. 2009;21(1):6-11.

23. Tanaka M, Misawa E, Yamauchi K, Abe F, Ishizaki C. Effects of plant sterols derived from Aloe vera gel on human dermal fibroblasts in vitro and on skin condition in Japanese women. Clin Cosmet Investig Dermatol. 2015;8:95-104.

24. Elsner P, Wilhelm D, Maibach HI. Mechanical properties of human forearm and vulvar skin. Br J Dermatol. 1990;122(5):607-614.

25. Lavker RM, Zheng PS, Dong G. Aged skin: a study by light, transmission electron, and scanning electron microscopy. J Invest Dermatol. 1987;88(3 suppl):44s-51s.

26. Escoffier C, de Rigal J, Rochefort A, Vasselet R, Lévêque JL, Agache PG. Age-related mechanical properties of human skin: an in vivo study. J Invest Dermatol. 1989;93(3):353-357.
27. Makrantonaki E, Bekou V, Zouboulis CC. Genetics and skin aging Dermatoendocrinol. 2012;4(3):280-284.

28. Makrantonaki E, Brink TC, Zampeli V, et al. Identification of biomarkers of human skin aging in both genders. Wnt signaling - a label of skin aging? PLoS One. 2012;7(11):e50393.

29. Bernerd F, Vioux C, LeJeune F, Asselineau D. The sun protection factor (SPF) inadequately defines broad spectrum photoprotection: demonstration using skin reconstructed in vitro exposed to UVA, UVB or UV-solar simulated radiation. Eur J Dermatol. 2003;138(3):242-249.

30. Cerimele D, Celleno L, Serri F. Physiological changes in ageing skin. Br J Dermatol. 1990;122(35):13-20.

31. Hwang KA, Yi BR, Choi KC. Molecular mechanisms and in vivo mouse models of skin aging associated with dermal matrix alterations. Lab Anim Res. 2011;27(1):1-8.

32. Jenkins G. Molecular mechanisms of skin ageing. Mech Ageing Dev. 2002;123(7):801-810.

33. Hamman JH. Composition and applications of Aloe vera leaf gel. Molecules. 2008;13(8):1599-1616.

34. Rodríguez RE, Darias MJ, Díaz RC. Aloe vera as a functional ingredient in foods. Crit Rev Food Sci Nutr. 2010;50(4):305-326. 


\section{Supplementary material}

Table SI Sun exposure time of subject

\begin{tabular}{llllll}
\hline Sun exposure habit (hours per day) & Group & $\mathbf{n}$ & $\mathbf{0 - 4}$ weeks, $\mathbf{n}(\%)$ & $\mathbf{4 - 8}$ weeks, $\mathbf{n}(\%)$ & $\mathbf{8 - 1 2}$ weeks, $\mathbf{n}(\%)$ \\
\hline $2-5^{*}$ & Aloe sterol & 23 & $21(91.3)$ & $16(69.6)$ & $13(56.5)$ \\
& Placebo & 24 & $17(73.9)$ & $14(60.9)$ & $7(30.4)$ \\
$<2$ & Aloe sterol & 23 & $2(8.7)$ & $7(30.4)$ & $10(43.5)$ \\
& Placebo & 24 & $7(29)$ & $10(42)$ & $17(71)$ \\
\hline
\end{tabular}

Note: *Each subject was instructed to expose his arm to sunlight every day for 2-5 hours.

\section{Publish your work in this journal}

Clinical, Cosmetic and Investigational Dermatology is an international, peer-reviewed, open access, online journal that focuses on the latest clinical and experimental research in all aspects of skin disease and cosmetic interventions. This journal is included on PubMed. The manuscript management system is completely online and includes a very quick and fair peer-review system, which is all easy to use. Visit http://www.dovepress.com/testimonials.php to read real quotes from published authors 